\title{
O ensino remoto e a aprendizagem dos discentes em tempos de Covid-19: o discurso dos docentes de uma instituição de ensino do estado do Paraná
}

\author{
Remote education and student learning in times of Covid-19: the speech of teachers of a teaching \\ institution in the state of Paraná
}

La educación a distancia y el aprendizaje de los alumnos en tiempos del Covid-19: el discurso de los maestros de una institución docente del estado de Paraná

Recebido: 16/12/2021 | Revisado: 22/12/2021 | Aceito: 25/01/2022 | Publicado: 26/01/2022

\author{
Adelaide de Oliveira Silva \\ ORCID: https://orcid.org/0000-0002-2236-0416 \\ Secretaria de Estado da Educação do Paraná, Brasil \\ E-mail: adelaideos@hotmail.com \\ Raquel Rosan Christino Gitahy \\ ORCID: https://orcid.org/0000-0002-5387-9536 \\ Universidade do Oeste Paulista, Brasil \\ Universidade Estadual do Mato Grosso do Sul, Brasil \\ E-mail: raquelgitahy.rg@gmail.com
}

\begin{abstract}
Resumo
O presente artigo teve como objetivo geral analisar a percepção de um grupo de docentes do Ensino Fundamental e Médio de uma instituição educacional do estado do Paraná sobre o processo de aprendizagem de discentes durante o ensino remoto ocorrido na pandemia do Covid-19. A metodologia foi qualitativa, do tipo estudo de caso. A coleta de dados ocorreu por meio de um questionário com 15 docentes do Ensino Fundamental e Médio de uma instituição da Rede Estadual do Paraná, a fim de verificar o perfil docente e a percepção sobre o processo de ensino remoto. Para a análise dos dados, utilizamos a técnica do Discurso do Sujeito Coletivo (DSC), com as ideias centrais apresentadas na categoria: ensino remoto e o processo de aprendizagem dos discentes. Os resultados demonstraram que as ações governamentais (criação do Aula Paraná, uso do Google Classroom, Business Intelligence) facilitaram a aprendizagem, porém esta não foi efetiva para todos os estudantes devido à falta de equipamento, internet ou dificuldade de adaptação.
\end{abstract}

Palavras-chave: Ensino remoto; Aprendizagem; Discentes; Tecnologia digital de informação e comunicação; Covid19.

\begin{abstract}
This article had as general objective to analyze the perception of a group of teachers from Elementary and High School of an educational institution in the state of Paraná about the learning process of students during remote teaching that took place in the Covid-19 pandemic. The methodology was qualitative, of the case study type. Data collection took place through a questionnaire with 15 elementary and high school teachers from an institution in the Paraná State Network, in order to verify the teacher profile and perception of the remote teaching process. For data analysis, we used the Collective Subject Discourse (DSC) technique, with the central ideas presented in the category: remote teaching and the students' learning process. The results showed that government actions (creation of Aula Paraná, use of Google Classroom, Business Intelligence) facilitated learning, but this was not effective for all students due to lack of equipment, internet or difficulty in adapting.
\end{abstract}

Keywords: Remote teaching; Learning; Students; Digital information and communication technology; Covid-19.

\section{Resumen}

Este artículo tuvo como objetivo general analizar la percepción de un grupo de profesores de Enseñanza Básica y Media de una institución educativa del estado de Paraná sobre el proceso de aprendizaje de los alumnos durante la enseñanza a distancia que se produjo en la pandemia de la Covid-19. La metodología fue cualitativa, del tipo estudio de caso. La recolección de datos se realizó a través de un cuestionario con 15 docentes de primaria y secundaria de una institución de la Red del Estado de Paraná, con el fin de verificar el perfil docente y la percepción del proceso de enseñanza a distancia. Para el análisis de los datos se utilizó la técnica del Discurso Colectivo del Sujeto (DSC), con las ideas centrales presentadas en la categoría: enseñanza a distancia y proceso de aprendizaje de los estudiantes. Los resultados mostraron que las acciones gubernamentales (creación de Aula Paraná, uso de Google Classroom, Business 
Intelligence) facilitaron el aprendizaje, pero esto no fue efectivo para todos los estudiantes por falta de equipamiento, internet o dificultad de adaptación.

Palabra clave: Enseñanza a distancia; Aprendiendo; Estudiantes; Tecnología de la información y las comunicaciones digitales; Covid-19.

\section{Introdução}

Na presente pesquisa, lançamos reflexões acerca do Ensino Remoto Emergencial (ERE) em tempos de pandemia no sistema regular de ensino da Rede Estadual do Paraná.

O ERE foi implantado em razão da pandemia da Covid-19, uma doença causada pelo novo coronavírus que, a partir do mês de fevereiro de 2020, passou a se espalhar pelo planeta e causar enormes prejuízos, principalmente pela necessidade do isolamento social para reduzir a circulação do vírus.

No tocante à necessidade de isolamento social, Oliveira e Souza (2020) asseveram que essa prática não é nova, tendo em vista que surgiu como forma de conter a gripe espanhola, em 1919. A estratégia ajudou na crise sanitária enfrentada naquele momento histórico e acredita-se ser uma "[...] importante medida a ser adotada pela população no combate ao novo coronavírus" (Oliveira \& Souza, 2020, p. 3).

Em uma época atípica, tal como a pandemia, os educadores se depararam com uma nova realidade em seus cotidianos professorais. De acordo com Santos Junior e Monteiro (2020, p. 3),

[...] com o avanço do número de casos de pessoas infectadas pela COVID-19, escolas públicas e privadas, da educação básica à superior, dos 26 estados brasileiros e do Distrito Federal, cumpriram as determinações do governo federal para a suspensão das aulas, conforme a Portaria nº. 343/2020.

Tal Portaria foi publicada no Diário Oficial da União, especificamente em 17 de março de 2020, orientando que deve ocorrer "[...] a substituição das aulas presenciais por aulas em meios digitais enquanto durar a situação de pandemia da Covid19" (Brasil, 2020, on-line). Conforme dados da Unesco, no mês de março de 2020, a pandemia já impactava "Quase 300 milhões de alunos já foram afetados em 22 países de três continentes pelo fechamento de escolas devido à expansão do coronavírus (covid-19)" (Unesco, 2020, on-line).

Ademais, Santos Júnior e Monteiro afirmam que:

Diante do ocorrido, as instituições de ensino estão buscando alternativas para a mediar o processo formativo de forma remota para dar continuidade às aulas. As tecnologias digitais se apresentam como recursos favoráveis para a mediação, sobretudo no que tange às diferentes possibilidades de transformar tais ferramentas em salas de aulas virtuais, que possibilitam a interação de alunos e professores (Santos Junior \& Monteiro, 2020, p. 4).

A pandemia exigiu dos docentes a ressignificação de suas práticas, de modo a atender as demandas pedagógicas para propiciar aos alunos um novo cenário de aulas por meio de plataformas. Ressignificar uma prática demanda um tempo consideravelmente extenso, todavia, em um momento de pandemia, os professores tiveram de aprender velozmente as especificidades das plataformas digitais, tais como: Google Meet, BI, Classroom e outras, o que possibilitou a esses profissionais uma reflexão acerca do verdadeiro significado do trabalho docente em uma época totalmente adepta à informação, à tecnologia, às mudanças de comportamentos dos alunos na busca por um conhecimento dinâmico, arrojado e diligente.

Diante do exposto, percebemos que a pandemia não influenciou somente o campo da saúde, como também o da educação, exigindo uma assídua busca por uma educação de qualidade. Como pontuou a Organização das Nações Unidas para 
a Educação, a Ciência e a Cultura, "[...] mais de 1,4 bilhão de estudantes no mundo todo foram afetados pelo fechamento das escolas em virtude da pandemia" (Unesco, 2020, on-line).

Dessa forma, em um curto espaço de tempo, entramos em uma era radicalmente nova de aprendizagem, na qual a educação se tornou virtual. Entretanto, para que jovens marginalizados não fossem prejudicados em sua educação, a exigência se concentrou em aspectos, como: inovação, parceria e altruísmo. Nesse contexto, a UNESCO apresenta a Coalização Global de Educação frente à Covid-19, cujos membros são: a família das nações unidas, as organizações da sociedade civil, as empresas de mídia e os parceiros da área de Tecnologia da Informação (TI), para a efetivação de uma educação de qualidade, com ferramentas e tecnologias ao combate de lacunas de conteúdo e conectividade.

Pelo fato de a educação ter se tornada virtual, a modalidade que ganhou espaço de forma significativa no período de pandemia foi o ensino remoto. Referente a essa categoria de ensino, Arruda (2020) evidencia uma conceituação bastante pertinente, na qual:

A educação remota emergencial pode ser apresentada em tempo semelhante à educação presencial, como a transmissão em horários específicos das aulas dos professores, nos formatos de lives. Tal transmissão permitiria a colaboração e participação de todos de forma simultânea, mas pode envolver a gravação das atividades para serem acompanhadas por alunos sem condições de assistir aos materiais naquele momento. Ela também pode envolver mais iniciativas da $\mathrm{EaD}$, implementando ferramentas assíncronas (que funcionam de forma não instantânea, como fóruns de discussão) e melhor estruturação de materiais. Pode também envolver a transmissão de conteúdos por TV, rádio ou canal digital estatal, de forma mais massiva e emergencial (Arruda, 2020, p. 266).

A partir desse conceito, é possível compreendermos que a educação remota passa a se tornar um meio fundamental, a fim de assegurar a relação entre alunos, professores e outros atores sociais provenientes do campo da Educação. Sobre a temática da educação remota, outros autores, como Moreira, Henriques e Barros (2020), promovem discussões e reflexões pertinentes, ressaltando que:

É no quadro das necessidades em relação à docência online que se devem definir políticas e criar programas de formação e de capacitação para todos os agentes educativos direcionados para o desenvolvimento de projetos de formação e educação digital que permitam realizar uma adequada transição deste ensino remoto emergencial para uma educação digital em rede de qualidade (Moreira; Henriques; Barros, 2020, p. 362).

No que concerne ao exposto, é possível depreendermos a importância de fomentar projetos de formação para os professores desenvolverem suas práticas pedagógicas na educação remota para, posteriormente, adequarem-se à oferta de uma educação digital em rede que seja, de fato, efetiva e frutífera. Ainda sobre a temática, Arruda (2020) assevera que:

O novo coronavírus produziu esse efeito, mas em uma velocidade bem mais intensificada, possivelmente pelas tecnologias digitais de informação e comunicação (TDIC), pois foi possível perceber que todo o mundo não se encontrava previamente preparado para os efeitos sociais, culturais, educacionais e econômicos gerados por esse vírus (Arruda, 2020, p. 258).

Não se pode discutir sobre educação remota sem se remeter à característica dos jovens dos tempos atuais, os quais são compreendidos como uma geração conectada. Assim, a educação remota se aproxima do contexto dos jovens que se utilizam de plataformas e aplicativos para acessarem determinados conteúdos.

Como enfatiza Lévy (1999, p. 62), o ciberespaço:

[...] permite a combinação de vários dispositivos e interfaces interativos, que favorecem a construção, tais como: o correio eletrônico, as conferências eletrônicas, o hiperdocumento compartilhado, os sistemas avançados de aprendizagem ou de trabalho cooperativo. 
Ainda nas palavras de Lévy (1999, p. 92), o ciberespaço pode ser entendido como:

[...] o espaço de comunicação aberto pela interconexão mundial dos computadores e das memórias dos computadores. Essa definição inclui o conjunto dos sistemas de comunicação eletrônicos (aí incluídos os conjuntos de redes hertzianas e telefônicas clássicas), na medida em que transmitem informações. Consiste de uma realidade multidirecional, artificial ou virtual incorporada a uma rede global, sustentada por computadores que funcionam como meios de geração de acesso.

Compete pontuarmos que o ensino remoto surge para acompanhar a demanda de distanciamento físico em tempos de pandemia, pois se caracteriza como uma modalidade de ensino que transmite informação para a construção do conhecimento sem a presença física de professores e alunos, com a interação possibilitada pelo uso, por exemplo, das Tecnologias Digitais de Informação e Comunicação (TDIC).

Desde a gripe espanhola ocorrida em 1919, nenhuma outra pandemia influenciou tão decisivamente em termos de distanciamento físico, quanto a da Covid-19. Com isso, dentre tantas consequências trazidas por essa pandemia, o sistema educacional merece destaque, uma vez que, conforme consta em nossos incisivos legais, todo cidadão brasileiro tem direito à educação. Esse direito está previsto na Constituição Federal (Brasil, 1988), em seu Artigo 205, como segue:

A educação, direito de todos e dever do Estado e da família, será promovida e incentivada com a colaboração da sociedade, visando ao pleno desenvolvimento da pessoa, seu preparo para o exercício da cidadania e sua qualificação para o trabalho (Brasil, 1988, on-line).

Face à crise provocada por essa pandemia, o governo do estado do Paraná implantou, por meio do Decreto $\mathrm{n}^{\circ}$ 343/2020, o ensino remoto através da TV aberta, dos aplicativos Aula Paraná e Classroom, substituindo o ensino presencial em todo o estado. Segundo Oliveira e Souza (2020, p. 16),

[...] o sistema educacional, assim como todas as áreas da sociedade, busca alternativas para se adaptar à nova realidade, uma vez que, ainda não é possível definir quando essa crise será estabilizada e, com isso, a vida da população brasileira poderá seguir o seu fluxo. Diante de tantas incertezas, vem à tona a necessidade de pensar em estratégias que serão utilizadas para atenuar os impactos da crise provocada pela pandemia. Assim, surgem vários questionamentos, não só dos que estão na linha de frente, executando as atividades (gestores escolares, professores e toda a equipe multiprofissional envolvida no processo educacional, por exemplo, pedagogos, assistentes sociais, psicólogos, etc.), mas também daqueles que buscam traçar as diretrizes a serem seguidas.

Diante do contexto da pandemia, a tecnologia digital de informação e comunicação surge como uma alternativa viável para atenuar a situação de distanciamento físico.

Nesse âmago, destacamos que este estudo é um recorte de dissertação defendida em Programa de Mestrado em Educação no Brasil e nasceu da seguinte pergunta de pesquisa: segundo a percepção docente, como foi o processo de aprendizagem de discentes durante o ensino remoto no estado do Paraná devido à pandemia da Covid-19? A partir dessa questão, traçamos o objetivo geral de analisar a percepção de um grupo de docentes do Ensino Fundamental e Médio de uma instituição educacional do estado do Paraná sobre o processo de aprendizagem de discentes durante o ensino remoto.

\section{Metodologia}

A pesquisa foi baseada em uma abordagem qualitativa, do tipo estudo de caso. Por abordagem qualitativa, Gil (1999) entende que a ela enfatiza a historicidade dos fatos e o contexto social, de modo que o sujeito é considerado em sua singularidade e em suas particularidades, o que permite ao pesquisador investigar sua ação diante das situações e interações cotidianas. 
Empregamos a revisão integrativa, já que esta permite a combinação de dados da literatura empírica e teórica; por meio dessa junção, é possível criar, especificar e definir conceitos. Ademais, por intermédio da revisão integrativa, é possível encontrar lacunas sobre a temática pesquisada e responder às questões que ainda não foram respondidas.

Utilizamos o estudo de caso, caracterizado por retratar uma situação específica, um caso ou um evento. Trata-se de um estudo aprofundado de uma unidade particular, como uma pessoa, um grupo de pessoas, uma instituição, uma organização, ação política, social ou um evento cultural etc. Conforme postula Yin (1993), o estudo de caso pode ser do tipo exploratório, descritivo e explanatório. Assim, qualquer descoberta ou conclusão em um estudo de caso será mais contundente e categórica, porque envolve o uso de várias fontes, como asseverou o estudioso supracitado. "A orientação inicial do estudo de caso aponta para múltiplas fontes de evidência" (Yin, 1993, p. 67).

O grupo participante da pesquisa foi formado por 15 (quinze) docentes do Ensino Fundamental e Médio que atuam em uma mesma instituição nas áreas de Ciências Humanas, Ciência da Natureza, Linguagens e Matemática. Tais docentes trabalham em outras escolas do município, conhecendo as ações que envolvem a rede de ensino praticada em toda a cidade, o que torna esse grupo demasiadamente representativo, expressivo, característico e atuante. Por essa razão, além do fato de a pesquisadora atuar na instituição, essa escola foi escolhida como espaço onde será desenvolvido o estudo.

Destacamos como critérios utilizados para a inclusão dos participantes da pesquisa:

- docentes que vivenciaram o ensino remoto conhecido como Aula Paraná, o uso do Google Classroom e o controle do Business Intelligence $(B I)^{1}$;

- docentes que aceitaram fazer parte da pesquisa, assinando o Termo de Consentimento Livre e Esclarecido (TCLE).

A pesquisa iniciou após a aprovação do Comitê de Ética em Pesquisa (CEP), sendo que os docentes foram convidados e receberam a cópia impressa do TCLE com todas as informações. Tal termo foi entregue pela pesquisadora no momento que os docentes estiveram presencialmente na escola, o contexto da pesquisa. Após a entrega do termo impresso e com a sua leitura, os docentes que aceitaram participar da pesquisa, assinaram-no, recebendo uma cópia devidamente assinada também pela pesquisadora. Após esse processo, deu-se início à coleta de dados.

A pesquisa foi cadastrada na Coordenadoria de Pesquisa, Desenvolvimento e Inovação (CPDI) da Universidade do Oeste Paulista (UNOESTE), sob o número 6507, passando pela avaliação e aprovação do Comitê Assessor de Pesquisa. Foi cadastrado no Comitê de Ética e Pesquisa e na Plataforma Brasil, recebendo CAAE: 39505020.0.0000.5515.

\section{Resultados e Discussão}

Seguindo o definido no TCLE, mantivemos as identidades dos participantes preservadas a todo tempo, de modo que, para a melhor compreensão de suas concepções, empregamos os pseudônimos: Sujeito 1 (S1), Sujeito 2 (S2), Sujeito 3 (S3) etc.

Após o recebimento das respostas, empregamos o procedimento da análise do DSC, que é um mecanismo de investigação acadêmica englobado dentro das pesquisas qualitativas empenhadas na busca da compreensão das relações que se estabelecem em sociedade.

O DSC foi idealizado por Fernando Lefevre e Ana Maria Cavalcanti Lefevre, professores da Universidade de São Paulo (USP). Os procedimentos que envolvem o DSC compreendem o estudo e a investigação de depoimentos oriundos de

\footnotetext{
${ }^{1}$ Trata-se de ferramentas para monitorar dados, a fim de apoiar a tomada de decisão.
} 
questões abertas, reunindo as interlocuções com percepções semelhantes em discursos-síntese, compostos sempre na primeira pessoa do singular. Para Lefevre e Lefevre (2012, p. 1194):

[...] o discurso do sujeito coletivo, como técnica de processamento de depoimentos, consiste em reunir, em pesquisas sociais empíricas, sob a forma de discursos únicos redigidos na primeira pessoa do singular, conteúdos de depoimentos com sentidos semelhantes.

Já a organização das respostas que terminam na produção do DSC requer uma análise detalhada e um olhar analítico e descritivo, para que se determinem as ancoragens, que são as ideias centrais de cada resposta.

O DSC, como técnica para a análise dos dados obtidos por meio de pesquisas acadêmicas, gera representações sociais com grandes possibilidades e dimensões nas compreensões das percepções dos sujeitos participantes do estudo por seu caráter voltado às significações, o que "[...] permite tornar as representações mais ricas e mais claras, porque mais exemplificadas, mais detalhadas, mais justificadas" (Lefevre \& Lefevre, 2012, p. 1194). Entretanto, nesse mecanismo de coleta de dados, é preciso identificar os seguintes componentes de cada discurso: 1. Expressões-Chaves; 2. Ideias Centrais (ICs) e os Discursos do Sujeito Coletivo.

As Expressões-Chaves apresentam o âmago de cada depoimento, ou seja, a essência de cada discurso. Trata-se, portanto, dos excertos nas falas dos sujeitos participantes que melhor definem o conteúdo pesquisado.

As Ideias Centrais (ICs) são os trechos dos discursos que melhor expõem as representações de cada sujeito participante. Logo, nesta pesquisa, identificamos as concepções basilares para os questionamentos apresentados e agrupamos as ideias similares para compor, assim, o DSC.

Desse modo, o DSC se torna o resultado da concentração das Expressões-Chaves de cada depoimento, assim como das Ideias Centrais (ICs).

Ao longo de nossas discussões, despontam discursos que, em uma primeira análise, parecem contraditórios ou divergentes. Nesses casos, é preciso uma reflexão mais cuidadosa para compreendermos que, na verdade, todos os depoimentos selecionados se complementam e proporcionam a compreensão das percepções desse grupo de professores a respeito da instituição do processo de ensino remoto no estado do Paraná.

O Quadro 01 apresenta o questionamento que esse grupo de professores respondeu ao participar de nosso estudo, assim como a ideia central emergente, o que culminou na criação de categorias de análise e criação do DSC.

Quadro 1 - Ideia central emergente.

\begin{tabular}{|l|l|}
\hline \multicolumn{1}{|c|}{ Questionamento contemplados na pesquisa } & Ideias centrais emergentes \\
\hline O governo do estado do Paraná criou o Aula Paraná, & Construção da aprendizagem em tempos de ensino remoto e \\
além de fazer uso de recursos como o Google & uso das tecnologias digitais no processo educacional. \\
Classroom e o Business Intelligence [BI] para o & \\
ensino remoto, a fim de facilitar a aprendizagem dos & \\
estudantes. Na sua opinião, eles estão conseguindo & \\
isso ou não? Por quê?? & \\
\hline
\end{tabular}

Fonte: Dados da pesquisa (2021).

A fim de apreender o ponto de vista dos professores a respeito dos efeitos de multiplataformas de educação remota adotadas pelo estado do Paraná (Aula Paraná, Business Intelligence), assim como das aulas transmitidas pela televisão, pelo YouTube e por aplicativo com a utilização das ferramentas do Google, como o Classroom, o Meet e o Forms, perguntamos aos professores quais suas percepções a respeito da aprendizagem dos alunos utilizando, como meios, esses recursos. A indagação foi organizada da seguinte forma: o governo do estado do Paraná criou o Aula Paraná, além de fazer uso de recursos, como o Google Classroom e o Business Intelligence [BI] para o ensino remoto, a fim de facilitar a aprendizagem dos estudantes. Na 
sua opinião, eles estão conseguindo isso ou não? Por quê? As respostas dos participantes da pesquisa estão organizadas no Quadro 02, exposto a seguir.

Quadro 2 - Percepção dos professores sobre as ações governamentais e a aprendizagem dos estudantes.

\begin{tabular}{|c|c|c|}
\hline $\begin{array}{c}\text { Identificação do } \\
\text { participante }\end{array}$ & Expressões-chaves & Categoria \\
\hline $\mathrm{S} 1$ & $\begin{array}{l}\text { Acredito que sim. O recurso e meios foram implantados } \\
\text { para atender da melhor forma os alunos. Mas, sabemos } \\
\text { que ainda há dificuldade ao acesso via internet, devido a } \\
\text { série de situações particulares de cada aluno não só no } \\
\text { Estado do Paraná, mas também no Brasil todo. Então cabe } \\
\text { a todos da comunidade escolar fazer essa intensificação } \\
\text { para melhor poder atender o aluno em sua especificidade. }\end{array}$ & $\begin{array}{l}\text { A } \\
\text { As ações governamentais (criação do } \\
\text { Aula Paraná, uso do Google } \\
\text { Classroom, Business Intelligence) } \\
\text { facilitaram a aprendizagem, porém } \\
\text { não foi algo efetivo para todos os } \\
\text { estudantes devido à falta de } \\
\text { equipamento, internet ou dificuldade } \\
\text { de adaptação. }\end{array}$ \\
\hline S2 & $\begin{array}{l}\text { Parcialmente, porque nem todos os alunos tem acesso as } \\
\text { tecnologias digitais, nem interesse para aprender com } \\
\text { esses recursos, mas para aqueles que usam essas } \\
\text { ferramentas auxilia muito na aprendizagem. }\end{array}$ & $\begin{array}{l}\text { A } \\
\text { As ações governamentais (criação do } \\
\text { Aula Paraná, uso do Google } \\
\text { Classroom, Business Intelligence) } \\
\text { facilitaram a aprendizagem, porém } \\
\text { não foi algo efetivo para todos os } \\
\text { estudantes devido à falta de } \\
\text { equipamento, internet ou dificuldade } \\
\text { de adaptação. }\end{array}$ \\
\hline S3 & $\begin{array}{l}\text { Acredito que estão cumprindo com seu papel neste } \\
\text { momento de pandemia, mas não acredito que nossos } \\
\text { alunos tenham maturidade para realizar seus estudos de } \\
\text { modo remoto por muito tempo ainda. Entretanto os } \\
\text { recursos tecnologicos facilitam a aprendizagem. }\end{array}$ & $\begin{array}{l}\text { A } \\
\text { As ações governamentais (criação do } \\
\text { Aula Paraná, uso do Google } \\
\text { Classroom, Business Intelligence) } \\
\text { facilitaram a aprendizagem, porém } \\
\text { não foi algo efetivo para todos os } \\
\text { estudantes devido à falta de } \\
\text { equipamento, internet ou dificuldade } \\
\text { de adaptação. }\end{array}$ \\
\hline S4 & $\begin{array}{l}\text { Parcialmente, pois existem alunos que não tem acesso a } \\
\text { esses meios e vários outros que apesar do acesso, não tem } \\
\text { interesse ou motivação em estudar com essa metodologia. }\end{array}$ & $\begin{array}{l}\text { A } \\
\text { As ações governamentais (criação do } \\
\text { Aula Paraná, uso do Google } \\
\text { Classroom, Business Intelligence) } \\
\text { facilitaram a aprendizagem, porém } \\
\text { não foi algo efetivo para todos os } \\
\text { estudantes devido à falta de } \\
\text { equipamento, internet ou dificuldade } \\
\text { de adaptação. }\end{array}$ \\
\hline S5 & $\begin{array}{l}\text { Parcialmente. Existem vários pontos para serem } \\
\text { analisados em todo o contexto que a educação paranaense } \\
\text { tem vivenciado. Devemos partir do ponto em que não há } \\
\text { igualdade nas condições das famílias, ou seja, muitos não } \\
\text { possuem acesso a internet nem mesmo uma TV para } \\
\text { acompanhar as aulas na TV aberta, sendo assim o ensino } \\
\text { remoto não está atingindo cem por cento dos alunos. }\end{array}$ & $\begin{array}{l}\text { A } \\
\text { As ações governamentais (criação do } \\
\text { Aula Paraná, uso do Google } \\
\text { Classroom, Business Intelligence) } \\
\text { facilitaram a aprendizagem, porém } \\
\text { não foi algo efetivo para todos os } \\
\text { estudantes devido à falta de } \\
\text { equipamento, internet ou dificuldade } \\
\text { de adaptação. }\end{array}$ \\
\hline S6 & $\begin{array}{l}\text { O objetivo e ferramentas são boas, mas, muitos alunos não } \\
\text { conseguem acessar, devido a falta de instrumento para seu } \\
\text { uso (celular, notebook, computadores e internet). }\end{array}$ & $\begin{array}{l}\text { A } \\
\text { As ações governamentais (criação do } \\
\text { Aula Paraná, uso do Google } \\
\text { Classroom, Business Intelligence) } \\
\text { facilitaram a aprendizagem, porém } \\
\text { não foi algo efetivo para todos os } \\
\text { estudantes devido à falta de } \\
\text { equipamento, internet ou dificuldade } \\
\text { de adaptação. }\end{array}$ \\
\hline S7 & $\begin{array}{l}\text { Sim, a facilidade dessas tecnologias aumentou nossos } \\
\text { conhecimentos. }\end{array}$ & $\begin{array}{l}\text { A } \\
\text { As ações governamentais (criação do } \\
\text { Aula Paraná, uso do Google } \\
\text { Classroom, Business Intelligence) } \\
\text { facilitaram a aprendizagem, porém }\end{array}$ \\
\hline
\end{tabular}




\begin{tabular}{|c|c|c|}
\hline & & $\begin{array}{l}\text { não foi algo efetivo para todos os } \\
\text { estudantes devido à falta de } \\
\text { equipamento, internet ou dificuldade } \\
\text { de adaptação. }\end{array}$ \\
\hline S8 & $\begin{array}{l}\text { Para aqueles alunos que possuem acesso aos meios } \\
\text { tecnologicos sim, mas infelizmente nem todos estão } \\
\text { utilizando os recursos disponibilizados pelo estado. }\end{array}$ & $\begin{array}{l}\text { A } \\
\text { As ações governamentais (criação do } \\
\text { Aula Paraná, uso do Google } \\
\text { Classroom, Business Intelligence) } \\
\text { facilitaram a aprendizagem, porém } \\
\text { não foi algo efetivo para todos os } \\
\text { estudantes devido à falta de } \\
\text { equipamento, internet ou dificuldade } \\
\text { de adaptação. }\end{array}$ \\
\hline S9 & $\begin{array}{l}\text { Nós temos muitos alunos que não estão participando, pois } \\
\text { tem dificuldades para acompanhar as aulas, seja por falta } \\
\text { de internet onde mora, ou não tem recursos tecnológicos, } e \\
\text { há em alguns casos a falta de interesse. }\end{array}$ & $\begin{array}{l}\text { A } \\
\text { As ações governamentais (criação do } \\
\text { Aula Paraná, uso do Google } \\
\text { Classroom, Business Intelligence) } \\
\text { facilitaram a aprendizagem, porém } \\
\text { não foi algo efetivo para todos os } \\
\text { estudantes devido à falta de } \\
\text { equipamento, internet ou dificuldade } \\
\text { de adaptação. }\end{array}$ \\
\hline $\mathrm{S} 10$ & $\begin{array}{l}\text { Sim, as tecnologias educacionais é uma grande aliada da } \\
\text { educação, permitindo que os estudantes ampliem seus } \\
\text { conhecimentos, tornando-o mais flexível e dinâmico. }\end{array}$ & $\begin{array}{l}\text { A } \\
\text { As ações governamentais (criação do } \\
\text { Aula Paraná, uso do Google } \\
\text { Classroom, Business Intelligence) } \\
\text { facilitaram a aprendizagem, porém } \\
\text { não foi algo efetivo para todos os } \\
\text { estudantes devido à falta de } \\
\text { equipamento, internet ou dificuldade } \\
\text { de adaptação. }\end{array}$ \\
\hline S11 & $\begin{array}{l}\text { As ferramentas são ótimas para atender com um ensino de } \\
\text { qualidade, porém não atinge a maior parte dos estudantes. }\end{array}$ & $\begin{array}{l}\text { A } \\
\text { As ações governamentais (criação do } \\
\text { Aula Paraná, uso do Google } \\
\text { Classroom, Business Intelligence) } \\
\text { facilitaram a aprendizagem, porém } \\
\text { não foi algo efetivo para todos os } \\
\text { estudantes devido à falta de } \\
\text { equipamento, internet ou dificuldade } \\
\text { de adaptação. }\end{array}$ \\
\hline $\mathrm{S} 12$ & $\begin{array}{l}\text { Acredito que sim. Os recursos e meios foram implantados } \\
\text { para atender da melhor forma os alunos. Mas, sabemos } \\
\text { que ainda há dificuldade ao acesso via internet, devido a } \\
\text { série de situações particulares de cada aluno não só no } \\
\text { Estado do Paraná, más também no Brasil todo. Então cabe } \\
\text { a todos da comunidade escolar fazer essa intensificação } \\
\text { para melhor poder atender o aluno em sua especificidade. }\end{array}$ & $\begin{array}{l}\text { A } \\
\text { As ações governamentais (criação do } \\
\text { Aula Paraná, uso do Google } \\
\text { Classroom, Business Intelligence) } \\
\text { facilitaram a aprendizagem, porém } \\
\text { não foi algo efetivo para todos os } \\
\text { estudantes devido à falta de } \\
\text { equipamento, internet ou dificuldade } \\
\text { de adaptação. }\end{array}$ \\
\hline S13 & $\begin{array}{l}\text { Sim, as ferramentas tecnológicas facilitam de forma } \\
\text { significativa a aprendizagem. }\end{array}$ & $\begin{array}{l}\text { A } \\
\text { As ações governamentais (criação do } \\
\text { Aula Paraná, uso do Google } \\
\text { Classroom, Business Intelligence) } \\
\text { facilitaram a aprendizagem, porém } \\
\text { não foi algo efetivo para todos os } \\
\text { estudantes devido à falta de } \\
\text { equipamento, internet ou dificuldade } \\
\text { de adaptação. }\end{array}$ \\
\hline S14 & $\begin{array}{l}\text { Em uma grande parcela da população não, porque muitos } \\
\text { não dispõem de condiçóes tecnológicas, financeiras e } \\
\text { pessoais para fazer esse acompanhamento. }\end{array}$ & $\begin{array}{l}\text { A } \\
\text { As ações governamentais (criação do } \\
\text { Aula Paraná, uso do Google } \\
\text { Classroom, Business Intelligence) } \\
\text { facilitaram a aprendizagem, porém } \\
\text { não foi algo efetivo para todos os } \\
\text { estudantes devido à falta de } \\
\text { equipamento, internet ou dificuldade } \\
\text { de adaptação. }\end{array}$ \\
\hline
\end{tabular}




\begin{tabular}{|l|l|l|}
\hline S15 & Estas ferramentas tecnológicas ajudam muito na & A \\
& aprendizagem daqueles que utilizam tais meios, mas & As ações governamentais (criação do \\
sabemos que a cultura digital não é acessível a todos os & Aula Paraná, uso do Google \\
& alunos. Precisamos lutar por políticas públicas voltadas \\
& para a inclusão digital dos estudantes. & $\begin{array}{l}\text { Classoom, Business Intelligence) } \\
\text { facilitaram a aprendizagem, porém } \\
\text { não foi algo efetivo para todos os } \\
\text { estudantes devido à falta de } \\
\text { equipamento, internet ou dificuldade } \\
\text { de adaptação. }\end{array}$ \\
\hline
\end{tabular}

Fonte: Dados da pesquisa (2021).

Quanto às respostas para esse questionamento, notamos que todos os professores participantes do estudo afirmaram que a criação do Aula Paraná e o uso do Google Classroom e do Business Intelligence influenciaram, positivamente, a aprendizagem dos estudantes. Entretanto, é preciso ter cuidado quanto à limitação no alcance dessas ferramentas, já que a prática não foi efetiva para todos os estudantes, tendo em vista que muitos sofrem com a falta de equipamento, internet ou dificuldade de adaptação.

A análise do Quadro 3 revela que os professores participantes da pesquisa acreditam que os recursos midiáticos e tecnológicos adotados pelo estado do Paraná, como o Aula Paraná, o Google Classroom e o Business Inteligente [BI], estão facilitando a aprendizagem no cenário da pandemia. No entanto, esses docentes dão ênfase, também, ao fato de que nem todos os estudantes têm acesso a essas ferramentas.

Quadro 3 - O discurso do sujeito coletivo.

\begin{tabular}{|c|c|c|c|c|}
\hline Categoria & Ideia central & Discurso do sujeito coletivo & $\begin{array}{l}\text { Quant. de } \\
\text { sujeitos }\end{array}$ & $\%$ \\
\hline A & $\begin{array}{c}\text { As ações } \\
\text { governamentais } \\
\text { (criação do Aula } \\
\text { Paraná, uso do } \\
\text { Google } \\
\text { Classroom, } \\
\text { Business } \\
\text { Intelligence) } \\
\text { facilitaram a } \\
\text { aprendizagem, } \\
\text { porém não foi } \\
\text { algo efetivo para } \\
\text { todos os } \\
\text { estudantes devido } \\
\text { à falta de } \\
\text { equipamento, } \\
\text { internet ou } \\
\text { dificuldade de } \\
\text { adaptação. }\end{array}$ & $\begin{array}{l}\text { Eu acredito que sim. Os objetivos das ferramentas são } \\
\text { bons. A facilidade dessas tecnologias aumentou os } \\
\text { nossos conhecimentos. Os recursos e meios foram } \\
\text { implantados para atender da melhor forma os alunos. } \\
\text { Mas, sabemos que ainda há dificuldade ao acesso via } \\
\text { internet, devido a série de situações particulares de } \\
\text { cada aluno não só no Estado do Paraná, mas também } \\
\text { no Brasil todo. Então cabe a todos da comunidade } \\
\text { escolar fazer essa intensificação para melhor poder } \\
\text { atender o aluno em sua especificidade. As ferramentas } \\
\text { estão cumprindo com seu papel neste momento de } \\
\text { pandemia, mas não acredito que nossos alunos tenham } \\
\text { maturidade para realizar seus estudos de modo remoto } \\
\text { por muito tempo. Alguns alunos sim, porque têm acesso } \\
\text { à tecnologia e orientação dos profissionais das escolas. } \\
\text { Principalmente, aqueles que querem aprender. Estas } \\
\text { ferramentas tecnológicas ajudam muito na } \\
\text { aprendizagem daqueles que utilizam tais meios, mas, } \\
\text { sabemos que a cultura digital não é acessível a todos } \\
\text { os alunos. Precisamos lutar por políticas públicas } \\
\text { voltadas para a inclusão digital dos estudantes. }\end{array}$ & 15 & $100 \%$ \\
\hline
\end{tabular}

Fonte: Dados da pesquisa (2021).

Nesse caso, organizamos apenas um Discurso do Sujeito Coletivo. O excerto mostra que esses profissionais acreditam que as plataformas estão facilitando a aprendizagem dos alunos do sistema de ensino paranaense, como pode ser analisado a seguir.

Eu acredito que sim. Os objetivos das ferramentas são bons. A facilidade dessas tecnologias aumentou os nossos conhecimentos. Os recursos e meios foram implantados para atender da melhor forma os alunos. Mas, sabemos que ainda há dificuldade ao acesso via internet, devido a série de situações particulares de cada aluno não só no Estado do Paraná, mas também no Brasil todo. Então cabe a todos da comunidade escolar fazer essa intensificação para melhor poder atender o aluno em sua especificidade. As ferramentas estão cumprindo com seu papel neste momento 
de pandemia, mas não acredito que nossos alunos tenham maturidade para realizar seus estudos de modo remoto por muito tempo, principalmente, aqueles que querem aprender. Estas ferramentas tecnológicas ajudam muito na aprendizagem daqueles que utilizam tais meios, mas sabemos que a cultura digital não é acessível a todos os alunos. Precisamos lutar por políticas públicas voltadas para a inclusão digital dos estudantes (DSC, 2021, s. p.).

Notadamente, torna-se comum que as ideias centrais desses participantes remetam ao fato de que nem todos os alunos dispõem de mecanismos tecnológicos para realizarem as atividades propostas, como falas evidenciadas dos participantes S4, S5, S6, S9, S10 e S15.

O S4 afirma que "[...] existem alunos que não têm acesso a esses meios [...]", ao passo que o S5 destaca que “Devemos partir do ponto em que não há igualdade nas condições das famílias”. Já o S6 chama a atenção para o fato de que “[...] muitos alunos não conseguem acessar, devido a falta de instrumento para seu uso (celular, notebook, computadores e internet)". O S9 reafirma essa ideia quando lembra que "Nós temos muitos alunos que não estão participando, pois tem dificuldades para acompanhar as aulas, seja por falta de internet onde mora, ou não têm recursos tecnológicos" e "[...] muitos não possuem celulares [...]".

O S15, além de mencionar a ausência de meios tecnológicos que possam atender a todos os estudantes, aponta para a carência que muitas crianças vivenciam, o que torna necessária a intervenção do Estado com políticas públicas que possam auxiliar na distribuição desses mecanismos.

S15: Estas ferramentas tecnológicas ajudam muito na aprendizagem daqueles que utilizam tais meios, mas, sabemos que a cultura digital não é acessível a todos os alunos. Precisamos lutar por políticas públicas voltadas para a inclusão digital dos estudantes (Expressão-chave do Sujeito 15).

Esses professores acreditam na aprendizagem adequada por meio das TDIC, levando-se em consideração o atual cenário educacional. Porém, cada um deles trouxe para o seu discurso ideias centrais no tocante à dificuldade de acesso, como é o caso do S1, ao destacar que "Acredito que sim. Os recursos e meios foram implantados para atender da melhor forma os alunos. Mas sabemos que ainda há dificuldades quanto ao acesso via internet, devido a uma série de situações particulares de cada aluno não só no estado do Paraná, más também no Brasil todo". Ou, como ressalta o S6: "O objetivo e ferramentas são boas, mas, muitos alunos não conseguem acessar, devido a falta de instrumento para seu uso (celular, notebook, computadores e internet)". Ou seja, os docentes acreditam que as ferramentas tecnológicas facilitam a aprendizagem; entretanto, deve-se considerar a falta de equipamento, internet ou dificuldade de adaptação que tanto estudantes como professores enfrentam. Sobre o tema, destacamos a afirmativa de Branco et al. (2020, p. 330):

É importante destacar que embora os avanços tecnológicos venham ocorrendo de forma exponencial, sobretudo nas últimas décadas, esses recursos nem sempre chegam, ou estão disponíveis para todas as classes sociais ou indivíduos. A internet, por exemplo, um recurso básico e essencial em um mundo cada vez mais digital, não está presente em todos os domicílios brasileiros, o que também provoca influências na educação.

Santos Junior e Monteiro (2020) analisam os recursos remotos, destacando o Google Classroom e o aplicativo ZOOM, assim como suas potencialidades pedagógicas para o ensino. Afirmam, entretanto, ser imprescindível continuarmos as reflexões e buscas de novas estratégias que amenizem as dificuldades de acesso aos recursos tecnológicos implantados pelo Estado. Métodos e políticas públicas capazes de promover o acesso a essas tecnologias digitais para que os alunos possam acompanhar as aulas, mesmo em condições não tão favoráveis. Segundo Branco et al. (2020, p. 330), quanto ao acesso à internet, "[...] mais de 20,0\% dos domicílios do país ainda não possuem este recurso. Nas Regiões Norte e Nordeste a situação é ainda mais crítica, sendo que cerca de 30,0\% dos domicílios ainda não contam com este serviço". 
Nesse contexto, o acesso aos meios tecnológicos representa o maior desafio do sistema de educação, não apenas paranaense, mas de todo o Brasil. Deve-se, portanto, refletir sobre a função essencial da escola de possibilitar a formação do sujeito, sem qualquer tipo de distinção, e criar políticas que favoreçam o acesso a essa nova escola, cujas tecnologias se tornaram um dos grandes mecanismos para facilitar a aprendizagem.

Isto é, diante do cenário da pandemia, novos desafios despontaram no fazer educativo, dentre eles, a superação das demandas por melhor infraestrutura e disponibilização das ferramentas tecnológicas que envolvem o ensino.

Carvalho (2012, p. 197) reflete sobre a importância das TDIC no ensino e para a conexão do estudante com o mundo, ressalvando que "[...] o importante é pensar não na tecnologia em si, como prótese ou extensão, mas como um processo contínuo de delegação e distribuição das atividades cognitivas, linguísticas e afetivas que formam uma rede com os diversos 'dispositivos' não humanos". Reafirmando este pensamento, Castells (1999, p. 35) destaca que "As tecnologias da informação, junto com a habilidade para usá-las e adaptá-las, são o fator crítico para gerar e possibilitar acesso à riqueza, poder e conhecimento no nosso tempo".

Libanio, Castelar e Garcia (2022, p. 4) salientam, ainda, que

[...] recursos tecnológicos podem ser utilizados de acordo com as necessidades específicas de cada um, associados à proposta pedagógica selecionada. Visto que tais tecnologias propiciam o desenvolvimento de habilidades, assim como propõem práticas inovadoras na sala de aula e levam à otimização das condições de aprendizagem. Assim sendo, a utilização das TDIC na educação apresenta-se como promissora enquanto contribuinte para a qualidade da prática pedagógica.

Em síntese, a maioria dos professores participantes da pesquisa acredita que as ferramentas adotadas pelo estado do Paraná são eficazes para proporcionar a continuação do ensinamento dos conteúdos escolares e, consequentemente, a aprendizagem. Mas esses docentes lembram que as mudanças abruptas para a instalação do ensino remoto exigiram muito de cada um. Além de preparação para compreenderem tal ensino, tiveram de se preparar para acolher os alunos em suas ansiedades e sentimentos novos, durante o processo de ensino e aprendizagem, bem como o desenvolvimento de habilidades relacionadas à empatia e resiliência (Silva et al., 2021).

$\mathrm{O}$ desafio de todos terem acesso às ferramentas empregadas no ensino durante a pandemia também desvelou mazelas quanto à superficialidade da implantação desses recursos, pois, além de muitos professores terem dificuldade em lidar com essas ferramentas, existem muitos alunos que não conseguem realizar uma utilização efetiva, o que tende a acarretar, ainda mais, as desigualdades sociais.

Entretanto, é válido destacarmos que as TDIC se revelaram como uma possibilidade para a manutenção do calendário escolar, mesmo diante do fechamento das escolas. Libanio, Castelar e Garcia (2022, p. 4) afirmam que

[...] a inclusão das TDIC é benéfica, uma vez que a utilização das TDIC é um importante suporte para o desenvolvimento das habilidades e das funções psicológicas superiores. A mediação pedagógica, por meio das TDIC, é uma ferramenta de ensino e aprendizagem com o objetivo de promover interação, cooperação, comunicação e motivação de forma a diversificar e potencializar as relações interpessoais e intrapessoais do processo educativo e do sistema educacional.

O panorama apresentado desenvolve e valoriza, especialmente, a possibilidade de interação entre professores e alunos em um contexto mediado pelas tecnologias digitais.

\section{Considerações Finais}

Nesta pesquisa, analisamos a percepção de um grupo de docentes do Ensino Fundamental e Médio de uma instituição educacional do interior do estado do Paraná sobre o processo de aprendizagem dos estudantes em tempos de ensino remoto. 
Por meio de questionário enviado de forma on-line, esses profissionais falaram sobre suas representações e concepções em relação ao novo cenário educacional.

Os resultados dessas participações apontam para o fato de que as ações governamentais (criação do Aula Paraná, uso do Google Classroom, Business Intelligence) facilitaram a aprendizagem, porém não foram efetivas para todos os alunos, devido à falta de equipamento, internet ou dificuldade de adaptação.

A presente pesquisa inova no sentido de que, até esse momento, não há qualquer outro estudo acadêmico, cujo eixo da discussão seja a análise das percepções de um grupo de docentes do Ensino Fundamental e Médio de uma instituição educacional paranaense.

Por fim, esta pesquisa traz a confirmação de que as TDIC tiveram valor primordial durante a pandemia da Covid-19, pois, em função delas, foi possível a continuidade da conexão entre professores e alunos, possibilitando as interações de forma sincrônica, a partilha de experiências, de conhecimento, ideias, dúvidas, problemas, soluções.

Nesse ínterim, recomenda-se a produção de pesquisas que estabeleçam o objetivo de apresentar as percepções de diretores e coordenadores, por exemplo, a respeito das plataformas empregadas durante o ensino remoto em escolas do estado do Paraná, focando-se, essencialmente, nos aspectos positivos e/ou negativos para a condução das atividades pedagógicas.

\section{Referências}

Arruda, E. P. (2020). Educação remota emergencial: elementos para políticas públicas na educação brasileira em tempos de COVID-19. Em Rede - Revista de Educação a Distância, 7(1), 257-275. https://www.aunirede.org.br/revista/index.php/emrede/article/view/621

Branco, E. P., Zantatta, S. C., Branco, A. B. de G., \& Nagashima, L. A. (2018). A implantação da Base Nacional Comum Curricular no contexto das políticas neoliberais. Curitiba: Appris.

Brasil. (1988). Constituição da República Federativa do Brasil. Brasília, DF: Presidência da República. http://www.planalto.gov.br/ccivil_03/constituicao/constituicao.htm

Brasil. (1998). Resolução n. 2, de 7 de abril de 1988. Institui as Diretrizes Curriculares Nacionais para a Educação Básica. Ministério da Educação e do Desporto, Conselho Nacional de Educação, Câmara da Educação Básica.

Brasil (2018). Resolução n. 15, de 26 de julho de 2018. Dispõe sobre as normas de conduta no âmbito da execução do Programa Nacional do Livro e do Material Didático. Brasília, DF: Ministério da Educação, Fundo Nacional de Desenvolvimento da Educação, Conselho Deliberativo. https://www.fnde.gov.br/index.php/acesso-a-informacao/institucional/legislacao/item/11997-resolução-nº 15,-de-26-de-julho-de-2018

Brasil. (2020). Medida Provisória n. 934, de $1^{\circ}$ de abril de 2020. Estabelece normas excepcionais sobre o ano letivo da educação básica e do ensino superior decorrentes das medidas para enfrentamento da situação de emergência de saúde pública de que trata a Lei nº 13.979 , de 6 de fevereiro de 2020 . Brasília, DF: Presidência da República. https://abmes.org.br/arquivos/legislacoes/Medida-provisoria-934-2020-04-01.pdf

Brasil. (2020). Parecer n. 5, de 28 de abril de 2020. Reorganização do Calendário Escolar e da possibilidade de cômputo de atividades não presenciais para fins de cumprimento da carga horária mínima anual, em razão da Pandemia da COVID-19. Brasília, DF: Ministério da Educação, Conselho Nacional de Educação. https://abmes.org.br/legislacoes/detalhe/3116

Carvalho, J. M. (2012). Práticas pedagógicas nas múltiplas redes educativas que atravessam os Currículos. In: Libâneo, J. C., Alves, N. (Org.). Temas de Pedagogia: diálogos entre Didática e Currículo. São Paulo: Cortez.

Castells, M. (2013). A obsolescência da educação. https://www.youtube.com/watch?v=eb0cNrE3I5g

Gil, A. C. (1999). Como elaborar projetos de pesquisa. Atlas.

Lefèvre, F., \& Lefèvre, A. M. C. (2003). O discurso do sujeito coletivo: um novo enfoque em pesquisa qualitativa (desdobramentos). (2a ed.). Caxias do Sul: EDUCS.

Lefèvre, F., Lefèvre, A. M. C., \& Marques, M. C. C. (2009). Discurso do sujeito coletivo, complexidade e auto-organização. Ciência e saúde coletiva, Rio de Janeiro, 14(4), 1193-1204.

Lévy, P. (1999). Cibercultura. Editora 34.

Libanio, F. C., Castelar, W. A de S., \& Garcia, D. I. B. (2022). O uso de tecnologias junto ao público-alvo da educação especial no contexto educacional inclusivo. Research, Society and Development, 11(1), 1-16. https://rsdjournal.org/index.php/rsd/article/view/24668

Moreira, A. F. B., \& Kramer, S. (2007). Contemporaneidade, educação e tecnologia. Educação e Sociedade, 28(100), $1037-1057$.

Moreira, J. A., Henriques, S., \& Barros, D. M. V. (2020). Transitando de um ensino remoto emergencial para uma educação digital em rede, em tempos de pandemia. Dialogia, (34), 351-364. https://repositorioaberto.uab.pt/handle/10400.2/9756 
Research, Society and Development, v. 11, n. 2, e30711224824, 2022

(CC BY 4.0) | ISSN 2525-3409 | DOI: http://dx.doi.org/10.33448/rsd-v11i2.24824

Moreira, J. A., \& Schlemmer, E. (2020). Por um novo conceito e paradigma de educação digital onlife. Revista UFG, Goiânia, 20(26), 1-35.

Oliveira, H. do V. de., \& Souza, F. S. de. D. (2020). O conteúdo programático ao sistema de avaliação: reflexões educacionais em tempos de pandemia (covid19). Boca - Boletim de Conjuntura, Boa Vista, 2(5), 15-24.

Oliveira, J. B. A. (2015). Repensando a educação brasileira: o que fazer para transforma nossas escolas. São Paulo: Salta.

Paraná. (2012). Caderno de Expectativas de Aprendizagem. Curitiba, PR: Departamento de Educação Básica. http://www.educadores.diaadia.pr.gov.br/arquivos/File/diretrizes/caderno_expectativas.pdf

Paraná. (2018). Referencial Curricular do Paraná: princípios, direitos e orientações. Curitiba, PR: SEED - Secretaria de Estado da Educação do Paraná http://www.referencialcurriculardoparana.pr.gov.br/modules/conteudo/conteudo.php?conteudo=11

Paraná. (2020). Decreto n. 4.320, de 23 de março de 2020. Altera dispositivos do Decreto $n^{\circ} 4.312$, de 20 de março de 2020 e do Decreto $n^{\circ} 4.230$, de 16 de março de 2020. Curitiba, PR: Secretaria de Estado da Saúde. https://www.legisweb.com.br/legislacao/?id=391472

Santos, A. O. (2020). As tecnologias digitais de informação e comunicação - TDIC e o ensino de matemática nos anos iniciais do ensino fundamental proposta $\mathrm{da}$ base nacional comum curricular (BNCC). Anais do Congresso Internacional de Educação e Tecnologias. https://cietenped.ufscar.br/submissao/index.php/2020/article/view/1308/979

Santos, S. C. A. dos. (2015). Práticas pedagógicas da modalidade a distância e do ensino presencial: contribuições para ensino híbrido no Instituto Federal do Maranhão. 102 f. Dissertação (Mestrado em Ensino) - Universidade do Vale do Taquari, Univates, Lajeado.

Santos Junior, V. B. dos, \& Monteiro, J. C. da S. (2020). Educação e COVID-19: as tecnologias digitais mediando a aprendizagem em tempos de pandemia. Revista Encantar: Educação, Cultura e Sociedade, Bom Jesus da Lapa, 2, 1-15. http://www.revistas.uneb.br/index.php/encantar/article/download/8583/pdf

Silva, J. B. da. (2021). A utilização da experimentação remota como suporte para ambientes colaborativos de aprendizagem. Tese (Doutorado em Engenharia e Gestão do Conhecimento) - Centro Tecnológico, Universidade Federal de Santa Catarina, 2021.

Souza, K. R. et al. (2021). Trabalho remoto, saúde docente e greve virtual em cenário de pandemia. Trabalho, Educação e Saúde, Rio de Janeiro, 19, 1-14. http://www.scielo.br/scielo.php?script=sci_arttext\&pid=S1981-77462021000100401\&lng=en\&nrm=iso

Unesco - Organização das Nações Unidas para a Educação, a Ciência e a Cultura. (2020). Coalização Global. https://pt.unesco.org/covid19/educationresponse/globalcoalition?fbclid=IwAR2PYq3uXgGs56sc2zDs5U_GnGrZt3UaxLpTK9jKMacwoVdyh9XmKeLyp2M

Yin, R. (1993). Applications of case study research. Sage Publishing. 